\title{
Anti-Acid Biomimetic Dentine Remineralization Using Inorganic Silica Stabilized Nanoparticles Distributed Electronspun Nanofibrous Mats
}

\author{
Chuanzi Liu' \\ Zhichao Hao' \\ Tao Yang' \\ Fushi Wang ${ }^{2}$ \\ Feng Sun ${ }^{3}$ \\ Wei Teng'
}

'Hospital of Stomatology, Guangdong Provincial Key Laboratory of Stomatology, Institute of Stomatological Research, Guanghua School of Stomatology, Sun Yatsen University, Guangzhou, People's Republic of China; ${ }^{2}$ The State Key Laboratory Breeding Base of Basic Science of Stomatology (Hubei - MOST) \& Key Laboratory of Oral Biomedicine Ministry of Education, School \& Hospital of Stomatology, Wuhan University, Wuhan, People's Republic of China; ${ }^{3}$ Analysis and Testing Center, South China Normal University, Guangzhou, People's Republic of China
Correspondence: Wei Teng

Email tengwei@mail.sysu.edu.cn
Background: To manage the sharp pain of dentine hypersensitivity, various materials are utilized to conduct dentine remineralization. However, many prior materials are limited with their single function and complicated operations. In this study, silica and calcium (strontium) carbonates mineralized nano cellulose fibrous $(\mathrm{Si} / \mathrm{Ca}(\mathrm{Sr})-\mathrm{NCF})$ mat with the ability to release acid resistant and biomimetic mineralizational silica/calcium (strontium) carbonate coprecipitation nanoparticles $(\mathrm{Si} / \mathrm{Ca}(\mathrm{Sr}) \mathrm{NPs})$ were fabricated. The dentine occluding effects, antibacterial activity and cytocompatibility of the $\mathrm{Si} / \mathrm{Ca}(\mathrm{Sr})-\mathrm{NCF}$ mats were evaluated.

Methods: The $\mathrm{Si} / \mathrm{Ca}(\mathrm{Sr})-\mathrm{NCF}$ mats were fabricated by dipping the electrospun nano cellulose fiber (NCF) into silica and calcium (strontium) carbonate liquid. Physicochemical characterizations and ion release were confirmed by scanning electron microscopy (SEM), Fourier transform infrared spectroscopy (FTIR), ion release assays and transmission electron microscopy (TEM). Sixty dentine discs were randomly divided into five groups: 1 , blank NCF; $2, \mathrm{Si} /$ $\mathrm{Ca}(\mathrm{Sr}$ 0)-NCF; 3, Si/Ca(Sr 0.01)-NCF; 4, Si/Ca(Sr 0.05)-NCF; 5, Si/Ca(Sr 0.1)-NCF. Dentine discs were mineralized by the mats and observed with SEM immediately, after acid challenge and remineralized in artificial saliva. The releasing liquid was investigated by TEM and type I collagen model. Then, antibacterial property and cytocompatibility were evaluated.

Results: SEM and TEM results confirmed that the experiment mats continuously released amorphous $\mathrm{Si} / \mathrm{Ca}(\mathrm{Sr})$ NPs and consequently realized anti-acid dentine biomimetic remineralization. Homogeneous surface coverage and collagen intrafibrillar mineralization in strontium adding groups illustrated the mineralization effect was not only by in site precipitation, but also collagen heterogeneous nucleation. Additionally, acceptable antibacterial and cytocompatibility properties were illustrated in low and middle $\mathrm{Sr}^{2+}$ containing mats.

Conclusion: In vitro studies on human dentine discs and type I collagen demonstrated that $\mathrm{Si} / \mathrm{Ca}(\mathrm{Sr})-\mathrm{NCF}$ system was a multifunction system inducing anti-acid, biomimetic, antibacterial and cytocompatible dentine remineralization. This multifunction mat would be a promising DH treatment candidate for complicated exposed dentine surfaces.

Keywords: mineralization, silica, dentine hypersensitivity, strontium carbonates, electrospinning

\section{Introduction}

Dentine hypersensitivity (DH) is a sharp tooth pain condition in dentistry. ${ }^{1}$ Based on available studies, DH prevalence rate ranges from $10-30 \%$ of the general population and most of the sufferers are in their $20 \mathrm{~s}$ to $40 \mathrm{~s} .^{2,3}$ Irritated by daily activities such as air/water contact, acid food or toothbrushing, this frequent $\mathrm{DH}$ pain can be disruptive to basic life. ${ }^{2,3}$ For $\mathrm{DH}$ to occur, the outer enamel or 
cementum covering the dentine usually are destroyed with exposed surfaces which are susceptible to external chemical and mechanical stimulus. These irritations can trigger the dentine tubular fluid flow and induce the tooth pain via the excitation of pulp nerve fibers according to the widely accepted hydrodynamic theory. ${ }^{4,5}$

Nowadays there are two treatment strategies, namely, reducing the pulp nerve response and occluding the exposed dentine tubulars. ${ }^{6-8}$ Nerve paralysis agents, for example, potassium salts can interfere with the signaling in nerve receptors and relieve the sharp pain. However, the evidence based research failed to find obvious support for the subjective pain relief for the potassium salts. ${ }^{9}$ Alternatively, various materials are utilized to occluding the exposed dentine surfaces. ${ }^{6-8}$ Among the large number of strategies, biomimetic materials are in greater demand compared to the classic ion-based minerals such as calcium salts and phosphates in recent decades. ${ }^{8}$ Biomimetic materials, based on non-classical particle-based crystallization concept, are usually amorphous mineral precursor nanoparticles stabilized with non-collagenous protein analogs. ${ }^{10,11}$ With prolonged crystallization process and suitable aggregation sizes, the biomimetic mineralization controlled by organics presents obvious advantages over the violent crystallization by ion based process. ${ }^{8,12}$ Nevertheless, these organic-inorganic strategies still have drawbacks such as the lack of anti-acid property. Acid resistance is an important criterion for the stable existence of the occluding layers. ${ }^{2,6}$ Remineralization structure may be easily lost because of the daily acid food or tooth surface attrition during complicated oral activities. With anti-acid property, another important remineralization material is silicon based materials such as bioactive glass (BG). However, the BG induces rapid ion release with drastically increased $\mathrm{pH}$ value. ${ }^{13}$ Many of the prior materials are limited with their single function and complicated operations.

Inspired by silica/carbonate co-precipitation nanoparticles originated in natural mineral sedimentation, polymer silica is found to be a special inorganic precursor stabilizer recently. ${ }^{13}$ In the silica/carbonate co-precipitation nanoparticle, polymer silica shells and amorphous carbonate cores self-assemble with each other by electrostatic chemical compelling under silica rich and weak alkaline environment. ${ }^{15,16}$ Remarkably, this polymer silica skin can simultaneously be an anti-acid component and kinetically stabilize the inner amorphous carbonates. ${ }^{15,17}$ This simple silica shell would be a promising new silicon structure conducting anti-acid biomimetic mineralization.

In addition to the bifunctional silica shell, the inner cores of co-precipitation nanoparticles are alkaline cation carbonates such as calcium $(\mathrm{Ca})$ or barium $(\mathrm{Ba})$ carbonates which are commonly used mineralization components. ${ }^{14-16}$ With the aim to utilize an anti-acid biomimetic coprecipitation nano particle, the inner carbonates were further selected as mixed strontium ( $\mathrm{Sr}$ ) and calcium carbonates as the addition of $\mathrm{Sr}^{2+}$ is reported to enhance crystal anisotropy. ${ }^{18}$ Our previous research also suggested promoting osteogenic differentiation by adding $\mathrm{SrCO}_{3}{ }^{19}$

To release the silica/calcium (strontium) carbonate coprecipitation nanoparticles $(\mathrm{Si} / \mathrm{Ca}(\mathrm{Sr}) \mathrm{NPs})$ onto dentine surfaces, the present study developed an all-in-one strategy fabricating the mineralized nano cellulose fiber (NCF) mats which can release functional $\mathrm{Si} / \mathrm{Ca}(\mathrm{Sr}) \mathrm{NPs}$. NCF mats is a widely sourced and low-cost fiber and can be hydrolyzed from the electrospun cellulose acetate (CA) mats in alkaline solution. ${ }^{20}$ Benefit from the rich hydroxyl groups, NCF would provide quantity connecting positions and hydrophilicity would also make the membrane convenient to use. Based on the successful loading onto the negative charged membranes in previous research, dipping the hydrolyzed anionic NCF mats into the silica/carbonate co-precipitation liquid, may facilitate a NCF mat wrapping silica/carbonate particles as well. ${ }^{21}$ Herein, the present study coated the $\mathrm{Si} / \mathrm{Ca}(\mathrm{Sr})-\mathrm{NCF}$ s onto the exposed dentine surfaces with the hypothesis that the $\mathrm{Si} / \mathrm{Ca}(\mathrm{Sr})-\mathrm{NCF}$ mats can conduct anti-acid biomimetic dentine remineralization. Additionally, the antibacterial effects and response of human dental pulp cells (hDPCs) were investigated.

\section{Materials and Methods}

\section{Materials}

\section{Dentine Sample Preparation}

The present study was conducted in accordance with the Declaration of Helsinki. After being authorized by the hospital of stomatology, Wuhan University Ethics Committee (2019-B10), 100 human extracted molars and premolars were collected after the informed consents signed by patients or their legal guardians according to approved protocols for the use of hard tissue research and human dental pulp cell ( $\mathrm{hDPCs}$ ) culture. The dentine discs were cut perpendicularly along the occlusal-apical axis with a low-speed saw (Isomet, Buehler, Lake Bluff, USA) with the thickness of $1.0 \pm$ $0.1 \mathrm{~mm}$ and be sawed off between the pulp cavity and 
superficial enamel. The samples were polished with 600 -grit silicon carbide paper to $1.0 \mathrm{~mm}$ thickness. In order to remove the smear layer and simulate the exposed hypersensitive dentine surface, the polished samples were soaked into 0.5 M EDTA liquid in an ultrasonic bath for 2 min. $^{22,23}$

\section{Preparation of Mineralization Liquid}

$0.1 \mathrm{M}$ sodium metasilicate, $0.1 \mathrm{M}$ calcium chloride and 0.1 $\mathrm{M}$ sodium carbonate solution of $10 \mathrm{~mL}$ aqueous solution were mixed in centrifuge tubes. $0,0.01,0.05$ and 0.1 $\mathrm{M}$ strontium chloride were respectively added into four carbonate composition groups. The $\mathrm{pH}$ value was then adjusted to 10.5 with the $\mathrm{HCl}$ solution.

\section{Synthesis of Electrospinning NCF Mats}

NCF mats were fabricated by electrospinning of a $15 \mathrm{wt} \% \mathrm{CA}$ (Mn 30,000) and solution prepared in a 2/1 (wt/wt) acetone/N, $\mathrm{N}$-dimethylacetamide mixture according to the previous studies. ${ }^{20}$ Hydrolysis of the CA mats was implemented in a $0.05 \mathrm{M}$ sodium hydrate aqueous solution at ambient for 7 days and the CA mats were then transformed into NCF mats.

\section{Preparation of $\mathrm{Si} / \mathrm{Ca}(\mathrm{Sr})-\mathrm{NCF}$ Mats}

Five groups of NCF mats were dipped into different mineral liquid for 24 hours as following protocols:

group 1: blank NCF mats;

group 2: $\mathrm{Si} / \mathrm{Ca}(\mathrm{Sr} 0)-\mathrm{NCF}$ mats, $\mathrm{Sr}^{2+}$ free; group 3: $\mathrm{Si} / \mathrm{Ca}(\mathrm{Sr} 0.01)-\mathrm{NCF}$ mats, low $\mathrm{Sr}^{2+}$; group 4: $\mathrm{Si} / \mathrm{Ca}(\mathrm{Sr} 0.05)-\mathrm{NCF}$ mats, middle $\mathrm{Sr}^{2+}$; group 5: $\mathrm{Si} / \mathrm{Ca}(\mathrm{Sr} 0.1)-\mathrm{NCF}$ mats, high $\mathrm{Sr}^{2+}$.

The mats were dried in room temperature and applied onto dentine discs.

\section{Preparation of the Remineralized Dentine Discs}

After thorough inspection, teeth with cavity and defects were excluded and sixty discs divided into five groups were applied in the following experiments. The dentine discs with the mineralization mats were placed in petri dishes and were immersed in shallow purified water for 24 hours. Then, discs were picked out, and the covering mats were peeled off. There were twelve samples for each group for remineralization morphology, acid challenge and AS remineralization observation.

\section{Characterization of the $\mathrm{Si} / \mathrm{Ca}(\mathrm{Sr})-\mathrm{NCF}$ Remineralization System The Characterization of Si/Ca(Sr)-NCF Mats}

The morphology and physical and chemical properties of $\mathrm{Si} / \mathrm{Ca}(\mathrm{Sr})-\mathrm{NCF}$ mats were investigated with scanning electron microscopy (SEM; S-4800, Hitachi, Japan), Fourier transform infrared spectroscopy (FTIR; Thermo Nicollet 5700, USA) Raman spectra (i-Raman Portble Raman Spectrometer, B\&W TEK Inc, USA), drop shape analysis system CASTTR3.0 (USA KINO Industry Co., USA) and tensile test system Tex-ture Analyzer (TA.XT. plus, Stable Micro Systems, UK).

\section{Element Entrapment and Release Assay}

Newly synthesized $\mathrm{Si} / \mathrm{Ca}(\mathrm{Sr})-\mathrm{NCF}$ mats were collected and treated with hydrogen nitrite. After diluting, the solution samples were analyzed for concentration of $\mathrm{Ca}, \mathrm{Sr}$ and $\mathrm{Si}$ ions using an atomic absorption spectrophotometer (AAS; ContrAA 700, Analytik Jena AG, Germany). At time point day $0-3,4-6,7-9$ and $10-12$, the nonaccumulative and total concentration of ions released were investigated.

Then, the suspension released from the $\mathrm{Si} / \mathrm{Ca}(\mathrm{Sr})-\mathrm{NCF}$ mats instantly and after aging for 7 days were examined by transmission electron microscopy (TEM; JEOL JEM 2100, Japan) and the selected area electron diffraction (SAED). The releasing liquid for 7 days was dehydrated in ambient environment and exterminated by X-ray diffraction (XRD; X'Pert PRO, PANalytical, The Netherlands).

\section{The Characteristic of Remineralized Dentine Discs and Type I Collagen}

SEM observation was performed on $\mathrm{Si} / \mathrm{Ca}(\mathrm{Sr})-\mathrm{NCF}$ remineralized dentine discs, after acid leaching by $6 \mathrm{wt} \%$ citric acid for $1 \mathrm{~min}$ and after crystallization in artificial saliva (AS) for 7 days. The AS was prepared with $1.5 \mathrm{mM}$ calcium chloride, $50 \mathrm{mM}$ potassium chloride, $0.9 \mathrm{mM}$ monobasic potassium phosphate and $20 \mathrm{mM}$ Tris. ${ }^{21}$

The type I collagen fibers constructed on nickel mesh was stained by $0.1 \%$ uranyl acetate as the previous study. ${ }^{24}$ After immersing in the selected $\mathrm{Si} / \mathrm{Ca}(\mathrm{Sr})-\mathrm{NCF}$ mat releasing liquid for 6, 12 and 24 hours, the collagen fibers were observed by the TEM.

\section{In vitro Anti-Bacterial Ability}

To analyse the inner tubular antibacterial ability, Enterococcus faecalis (E. faecalis; ATCC 29212, ATCC, Manassas, VA, USA) was selected. Both sides of the mats $(6 \mathrm{~mm} \times 6 \mathrm{~mm})$ were disinfected for 1 hour under ultraviolet. The suspended bacteria colonies counting was conducted by coating the suspension evenly on agar plates after co-culturing for 6,12 and 24 hours. Plates with representative colony numbers were recorded in photos. 
The live bacteria colonies were quantified, and the antibacterial ratio (\%) was calculated.

\section{In vitro Cellular Studies Cell Proliferation}

Human dental pulp cells (hDPCs) were isolated from young patients' pulp tissue via improved explant culture. In-vitro cytotoxicity and morphology observation had been proceeded with 3-5 passage cells. Cell proliferation on the mats was determined using a cell counting kit-8 (CCK-8; Dojindo Laboratories, Japan) at 4 hours, 1, 4 and 7 days.

\section{Cell Adhesion and Morphology with $\mathrm{Si} / \mathrm{Ca}(\mathrm{Sr})-\mathrm{NCF}$ Mats}

At the time point of $24 \mathrm{~h}$ hours, the adhesion of cocultured cells with the material was observed under fluorescence microscopy (Leica DM4000B, Germany). Filamentous actins (F-actins) were stained with rhodamine phalloidin (R-415 kit, Invitrogen, USA) and the nuclei were stained with 2-(4-amidinophenyl)-6-indolecarbamidine dihydrochloride (DAPI; Invitrogen, Basel, Switzerland). The cell viability was evaluated by Live/ Dead assay with calcein-AM (Beyotime, China) and propidium iodide (PI; Beyotime, China).

\section{Alkaline Phosphatase (ALP) Activity and RT-qPCR for Osteogenesis-Related Gene Expression}

To evaluate the ALP activity, cells were cultured with hDPCs osteogenic factors which contains $100 \mathrm{nM}$ dexamethasone, $10 \mathrm{mM}$-glycerol phosphate and $50 \mathrm{~g} / \mathrm{mL}$ ascorbic acid (Sigma, USA). The total cellular lysate harvested on day 7 and day 14 was measured in alkaline buffer solution (A9226; Sigma Chemicals) with p-nitrophenyl phosphate (pNPP; Sigma, USA). Intracellular total protein content was determined via the BCA protein assay kit (Thermo Fisher Scientific, Waltham, MA). Then the ALP activity was normalized to the total protein content.

The gene expressions of osteogenesis related genes including ALP, osteocalcin (OCN), runt-related transcription factor 2 (Runx2), osteopontin (OPN) and glyceraldehyde 3-phosphate dehydrogenase (GAPDH) in hDPCs after osteogenic induction for 7 days were further evaluated by RT-qPCR according to the method in previous research.

\section{Statistical Analysis}

Statistical analysis was performed by SPSS 19.0 (SPSS Inc, USA). Results in ion release assay, CFU counting, CCK-8 and ALP experiments were analyzed using one- way ANOVA with post hoc Tukey's test, respectively. The significance level was set at $\alpha=0.05$.

\section{Result}

\section{Physicochemical Characterization of the} $\mathrm{Si} / \mathrm{Ca}(\mathrm{Sr})-\mathrm{NCF}$ Mats

\section{Surface Topography and Microstructural} Characterization

The electrospun NCF mats showed in loose woven form with smooth surfaces (Figure 1a1-a3). In Si/Ca( $\mathrm{Sr} 0)-\mathrm{NCF}$ group, acerose aggregations erupted from the granular aggregation attaching to the fibers and 10-20 $\mu \mathrm{m}$ diameter sphere particles were dispersed among the fibrous structure (Figure 1b1-b3). While in $\mathrm{Sr}^{2+}$ containing groups, no large bulk was detected. Denser acerose aggregations were presented in $\mathrm{Si} / \mathrm{Ca}(\mathrm{Sr} 0.01)-\mathrm{NCF}$ group (Figure 1c1-c3). In $\mathrm{Si} / \mathrm{Ca}(\mathrm{Sr} 0.05)-\mathrm{NCF}$ group, there were obvious segmented nano granular attachments onto the fibers (Figure 1d1d3). As for the images of $\mathrm{Si} / \mathrm{Ca}(\mathrm{Sr} 0.1)$-NCF group, the aggregation was more evenly attached onto the fibers (Figure 1e1-e3).

The undistinguished peak at $1750 \mathrm{~cm}^{-1}$ in NCF FTIR results implied the successful transformation from $\mathrm{CA}$ to NCF mats (Figure 2A). ${ }^{20}$ Peaks at $850 \mathrm{~cm}^{-1}\left(\mathrm{v}_{2}\right)$, and $1449 \mathrm{~cm}^{-1}\left(\mathrm{v}_{3}\right)$ representing the witherite or calcium carbonates further showed the existence of carbonates. Specially, the absence of $694 \mathrm{~cm}^{-1}\left(\mathrm{v}_{1}\right)$ peaks, with the peak splitting of $1449 \mathrm{~cm}^{-1}$ (splitting into $1420 \mathrm{~cm}^{-1}$ and $1450 \mathrm{~cm}^{-1}$ ) in all mineral groups further indicated that there are amorphous carbonates entrapping in the polymerized silica and NCF networks (Figure 2A). ${ }^{14,15}$ In the Raman spectrum, the peaks at $701 \mathrm{~cm}^{-1}$ and $1080 \mathrm{~cm}^{-1}$ also indicated the existence of alkali metal carbonates (Figure 2B). ${ }^{25}$ Additionally, the $\mathrm{Si} / \mathrm{Ca}(\mathrm{Sr})-\mathrm{NCF}$ hydrophilicity decreased as higher $\mathrm{Sr}^{2+}$ containing (Figure 2C) and the elastic modulus decreased with the combination of minerals as the result illustrated in Figure 2D, namely, 4.38 $\mathrm{MPa}$ in NCF, $1.82 \mathrm{MPa}$ in $\mathrm{Si} / \mathrm{Ca}(\mathrm{Sr} 0)-\mathrm{NCF}, 1.06$ $\mathrm{MPa}$ in $\mathrm{Si} / \mathrm{Ca}(\mathrm{Sr} 0.01)-\mathrm{NCF}, 0.98 \mathrm{MPa}$ in $\mathrm{Si} / \mathrm{Ca}(\mathrm{Sr} 0.05)$ $\mathrm{NCF}$ and $0.29 \mathrm{MPa}$ in $\mathrm{Si} / \mathrm{Ca}(\mathrm{Sr} 0.1)-\mathrm{NCF}$ mats.

\section{Element Entrapment and lon Release Assay}

The Sr entrapment varied in different groups (Figure 3Aac), and the noncumulative ion concentrations of $\mathrm{Sr}, \mathrm{Ca}$ and Si showed no evident burst release in the long-term observation (within 12 days) (Figure $3 \mathrm{Ad}-\mathrm{f}$ ). Within 12 days, the total $\mathrm{Sr}^{2+}$ release was tested as $0.48 \mathrm{mM}, 2.59 \mathrm{mM}$, and $4.75 \mathrm{mM}$ in the three $\mathrm{Sr}^{2+}$ groups. 

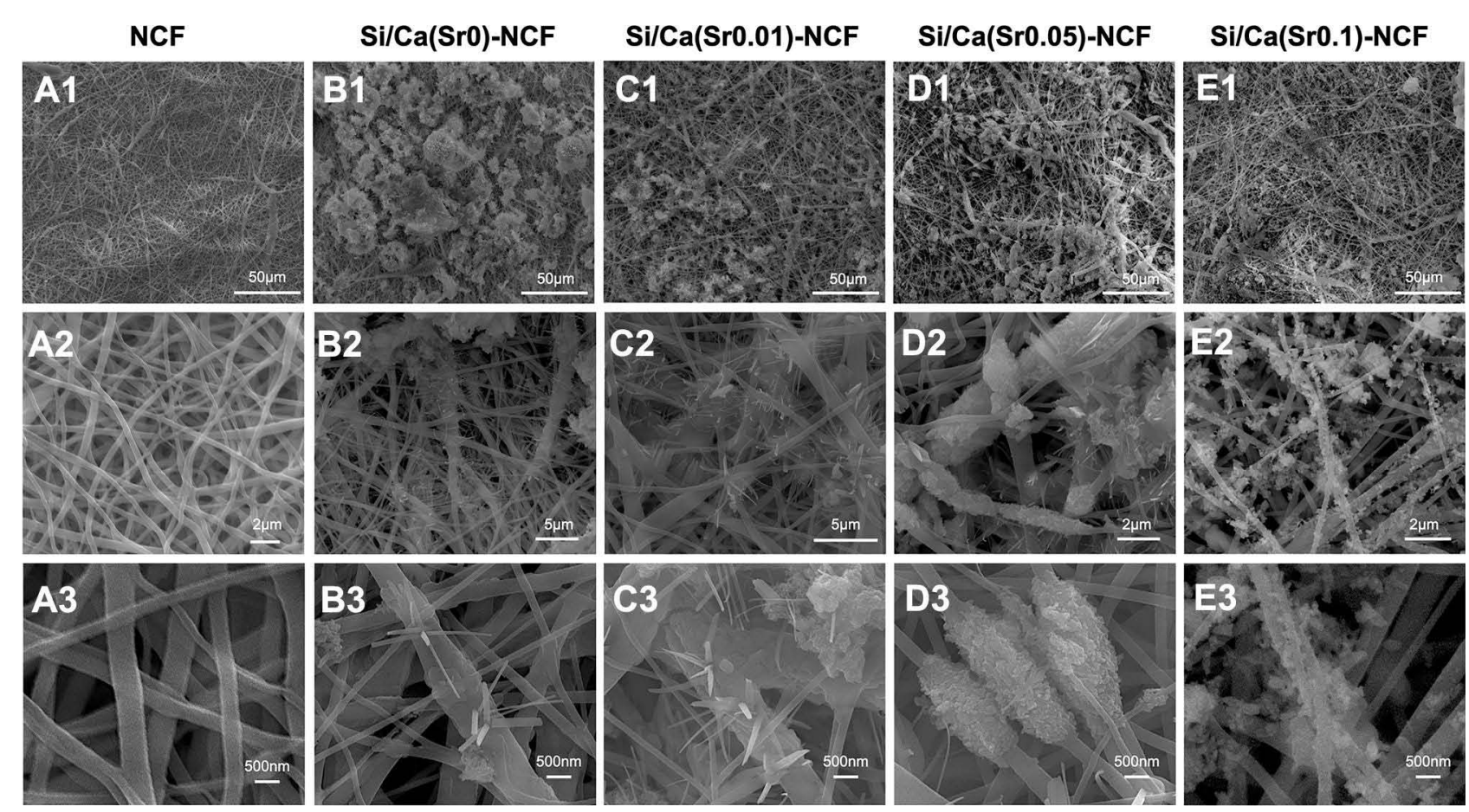

Figure I The SEM observation of Si/Ca(Sr)-NCF mats. SEM images of (AI-A3) control NCF mats, (BI-B3) Si/Ca(Sr 0)-NCF mats, (Cl-C3) $\mathrm{Si} / \mathrm{Ca}(\mathrm{Sr} 0.0 \mathrm{l})-\mathrm{NCF}$ mats, (DI-D3) $\mathrm{Si} / \mathrm{Ca}(\mathrm{Sr} 0.05)$-NCF mats and (EI-E3) $\mathrm{Si} / \mathrm{Ca}(\mathrm{Sr} 0.1)-\mathrm{NCF}$ mats.

Abbreviations: SEM, scanning electron microscopy; $\mathrm{NCF}$, nano cellulose fiber; $\mathrm{Si} / \mathrm{Ca}(\mathrm{Sr})-\mathrm{NCF}$, the nano cellulose fiber mineralized with silica and carbonates.

Liquid released immediately from the films was observed by TEM in Figure 3B. Si/Ca(Sr)-NCF mats with or without $\mathrm{Sr}^{2+}$ addition all presented nanoparticles with a diameter of approximately $50 \mathrm{~nm}$ (Figure 3Ba-d) with amorphous SAED patterns (Figure 3Be-h). The EDS results illustrated the $\mathrm{Ca} / \mathrm{Sr}$ containing in the releasing liquid showing the increasing $\mathrm{Sr}^{2+}$ containing (Figure 3Bi-1).

Liquid released from the representative $\mathrm{Sr}^{2+}$ containing group: $\mathrm{Si} / \mathrm{Ca}(\mathrm{Sr} 0.05)-\mathrm{NCF}$ group for 7 days was observed with TEM. After 7 days' coagulation, long columnar and small needle shaped crystals in the diluent were showed by TEM (Figure 3Cb and c) and SEM (Figure 3Ch and i). The $50 \mathrm{~nm}$ sized packed particles attaching to the crystal edge implied the existing of nanoparticles, which proposed the stabilization of amorphous carbonates for long-term (Figure 3Ca, c and d). Characteristic shell shedding phenomenon of $\mathrm{Si} / \mathrm{Ca}(\mathrm{Sr}) \mathrm{NPs}$ was also detected around the crystal edges (Figure 3Cc and d; red arrows) and SEM images further illustrated the accumulated shedding silica membrane wrapping the crystals and the aggregated nanoparticles (Figure 3Ci; red colored). This silica shell and membrane in aged liquid evidently demonstrated the coprecipitation growth behavior of the silica and the carbonates.
Next, in the lattice spacing analyses, (221) of calcite (PDF\# 51-1524) and the (021) of strontianite (PDF\# 05$0418)$ in $\mathrm{Si} / \mathrm{Ca}(\mathrm{Sr}$ 0.05)-NCF group were illustrated (Figure $3 \mathrm{Ce}$ and f). Corresponding XRD peaks at $31.82^{\circ}$ and $25.80^{\circ}$ were confirmed (Figure $3 \mathrm{Cg}$ ). Besides, the aragonite pattern (PDF\# 41-1475) at $27.35^{\circ}, 45.85^{\circ}$, $53.94^{\circ}$ and $66.19^{\circ}$ demonstrated in all groups implied the co-existence of aragonite and calcite.

\section{The Mineralization of in vitro Human Dentine Discs and Type I Collagen SEM Observation of Mineralized in vitro Human Dentine Disc}

In the dentine SEM images after remineralization by the $\mathrm{Si} / \mathrm{Ca}(\mathrm{Sr})-\mathrm{NCF}$ mats' coverage for 1 day, full surface occluding was presented in all $\mathrm{Sr}^{2+}$ adding groups (Figure 4A). While in $\mathrm{Sr}^{2+}$ free $\mathrm{Si} / \mathrm{Ca}(\mathrm{Sr} 0)-\mathrm{NCF}$ group, there were precipitations in peritubular dentine with partially patent tubular (Figure $4 \mathrm{Ab} 1$ and b2). In $\mathrm{Si} / \mathrm{Ca}(\mathrm{Sr}$ 0.01)-NCF and $\mathrm{Si} / \mathrm{Ca}(\mathrm{Sr} 0.05)-\mathrm{NCF}$ groups, 0.5-2.0 $\mu \mathrm{m}$ sized particles scattered on the homogeneous basal precipitation layer (Figure 4Ac1, c2, d1 and d2), while the large blade shaped crystals densely covered the full dentine surface in $\mathrm{Si} / \mathrm{Ca}(\mathrm{Sr}$ 0.1)-NCF group (Figure 4Ae1 and e2). The longitudinal sections showed corresponding 


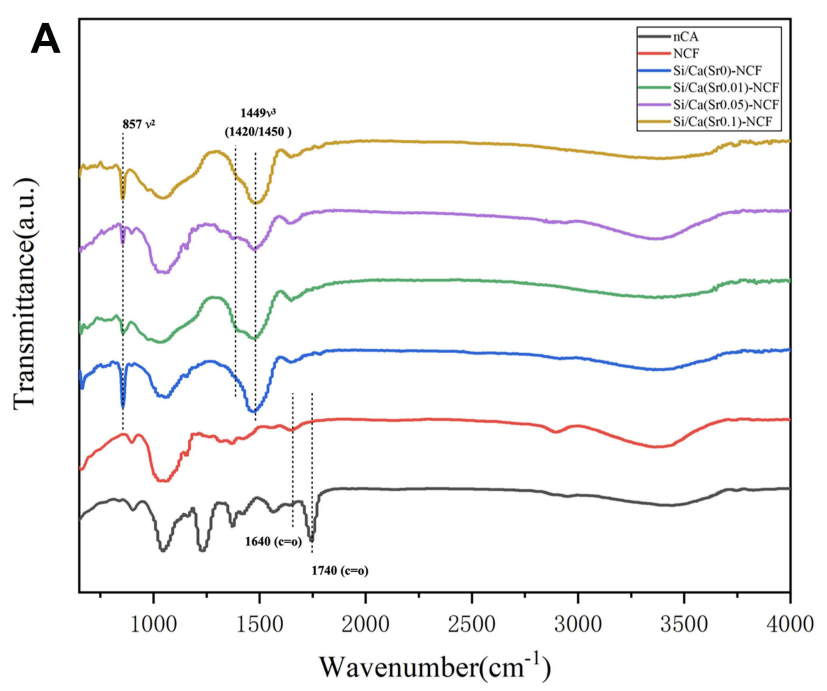

C

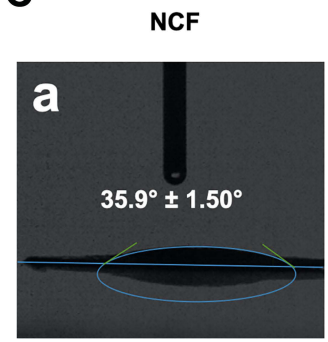

Si/Ca (Sr0.05)-NCF

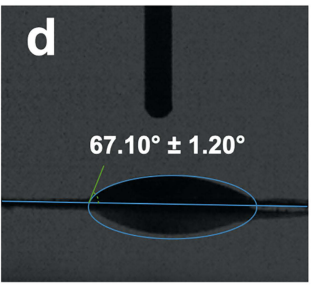

Si/Ca (Sr0)-NCF

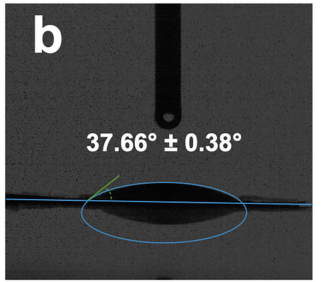

$\mathrm{Si} / \mathrm{Ca}(\mathrm{Sr} 0.1)-\mathrm{NCF}$

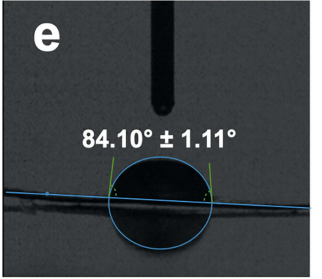

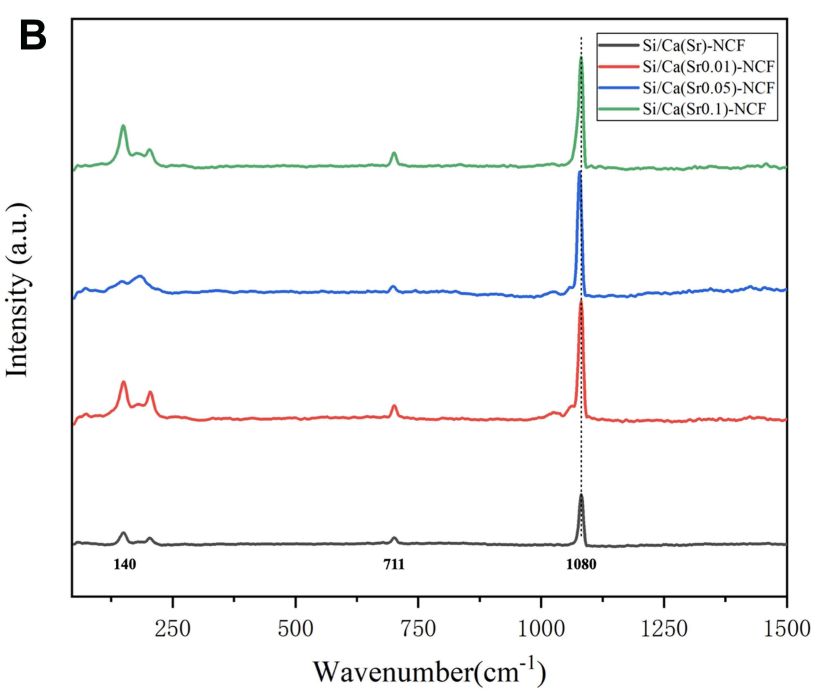

D

Si/Ca (Sr0.01)-NCF
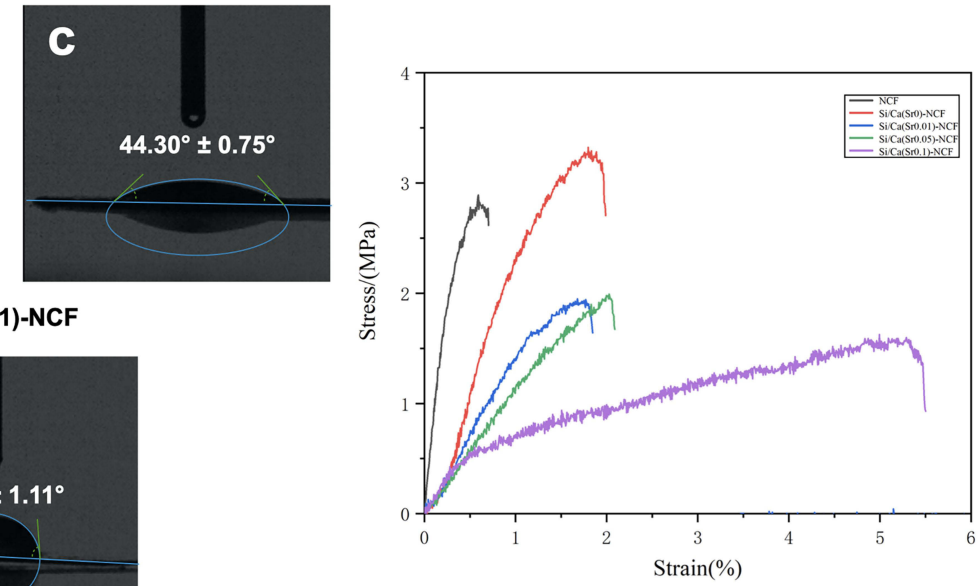

Figure 2 The FTIR, Raman spectrum, water contact angles and elastic tests of $\mathrm{Si} / \mathrm{Ca}(\mathrm{Sr})-\mathrm{NCF}$ mats. (A) FTIR spectrum of Si/Ca(Sr)-NCF mats. (B) FTIR spectrum of Si/ $\mathrm{Ca}(\mathrm{Sr})-\mathrm{NCF}$ mats. (C) water contact angles of $\mathrm{Si} / \mathrm{Ca}(\mathrm{Sr})-\mathrm{NCF}$ mats, (D) elastic tests for $\mathrm{Si} / \mathrm{Ca}(\mathrm{Sr})-\mathrm{NCF}$ mats.

Abbreviations: FTIR, Fourier transform infrared spectroscopy; NCF, nano cellulose fiber; $\mathrm{Si} / \mathrm{Ca}(\mathrm{Sr})-\mathrm{NCF}$, the nano cellulose fiber mineralized with silica and carbonates.

preferable results in low and middle $\mathrm{Sr}^{2+}$ containing groups: no longitudinal infiltration (Figure 4a3), $8 \mu \mathrm{m}$ in $\mathrm{Sr}^{2+}$ free group (Figure 4b3), $12 \mu \mathrm{m}$ in low $\mathrm{Sr}^{2+}$ group (Figure 4c3);20 $\mu \mathrm{m}$ in middle $\mathrm{Sr}^{2+}$ containing group (Figure $4 \mathrm{~d} 3$ ) and $6 \mu \mathrm{m}$ in high $\mathrm{Sr}^{2+}$ containing group (Figure 4e3).

Then, SEM images of acid challenge showed $\mathrm{Sr}^{2+}$ containing groups all presented better tubular obstruction than NCF and $\mathrm{Sr}^{2+}$ free groups after acid challenge (Figure 4B). The granular particles in $\mathrm{Sr}^{2+}$ containing groups were evident (Figure 4Bc1-c3, d1-d3, e1-d3) while the $\mathrm{Sr}^{2+}$ free group showed patent tubular openings (Figure 4Bb1-b3).
Immersing in the AS, the SEM images indicating denser full surface coverage in $\mathrm{Sr}^{2+}$ containing groups compared with residual groups (Figure 4C).

\section{TEM Observation of Mineralized in Type I Collagen Fibers}

Further exploration of type I collagen infiltration ability was conducted with the mineral liquid released from the representative $\mathrm{Si} / \mathrm{Ca}(\mathrm{Sr} 0.05)-\mathrm{NCF}$ mats. The amorphous SAED image changed at time point 1 hour (Figure 5A) changed into poly crystal rings after 6 and 12 hours (Figure 5B and C) implying the successful collagen infiltration mineralization. 

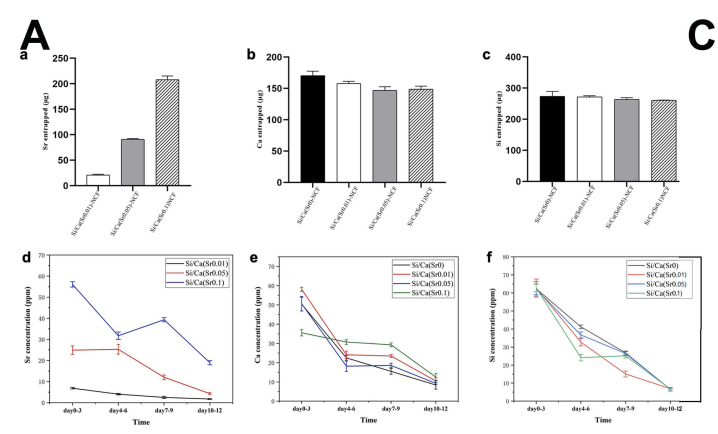

C
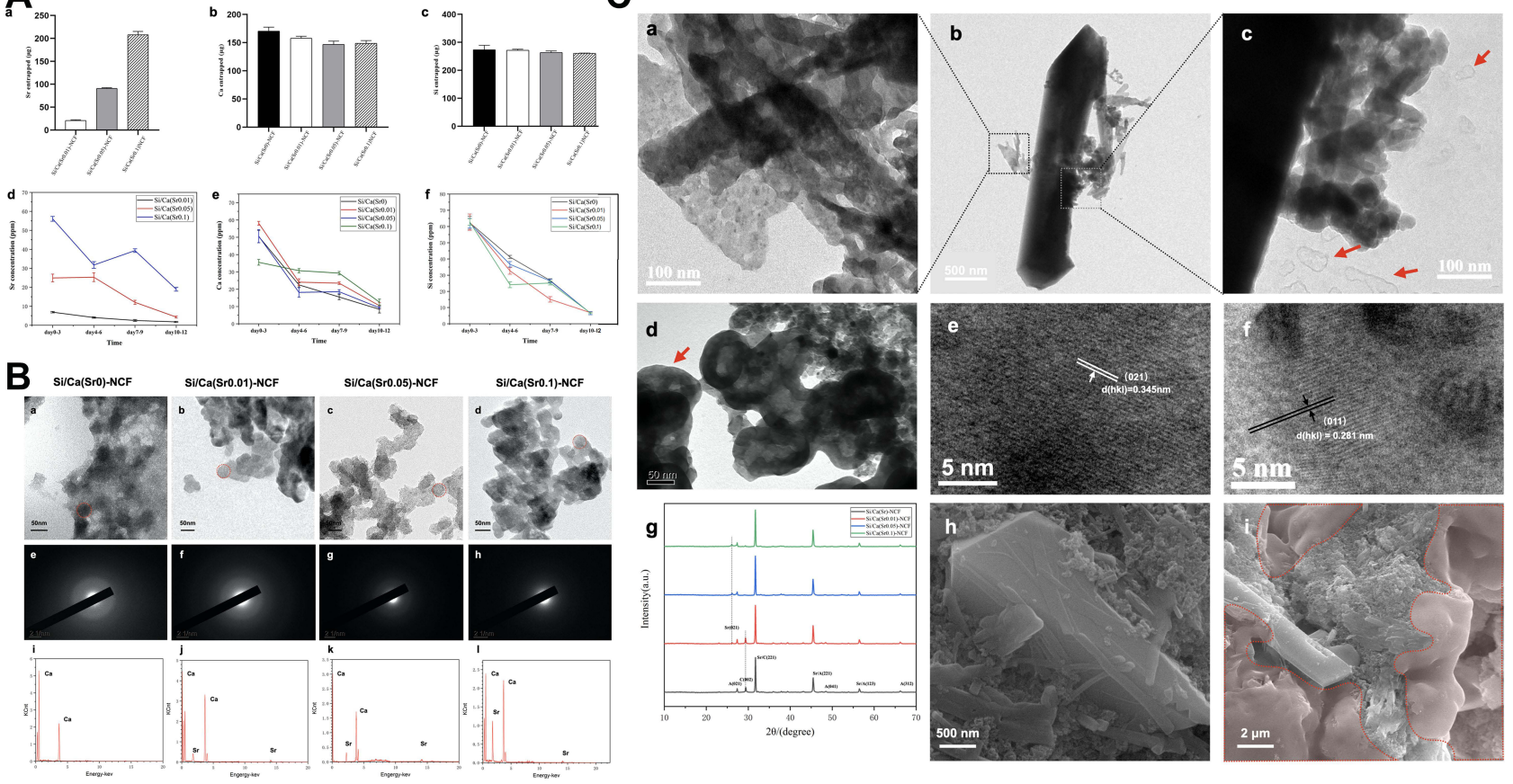

Figure 3 The ion release assay of $\mathrm{Si} / \mathrm{Ca}(\mathrm{Sr})-\mathrm{NCF}$ mats and the long-term crystallization. $(\mathbf{A})(\mathrm{a}-\mathrm{c}) \mathrm{Sr}, \mathrm{Ca}$, and $\mathrm{Si}$ ion entrapments and (d-f) nun-cumulative release of ions at day 0-3, day 4-6 and day 7-9. (B) (a-d) TEM images of the released liquid, (e-h) SAED patterns of the particles in different groups (red circles indicating the 50 nm sized particles) and (i-l) EDS results of the nanoparticles of different groups. (C) Crystallization after aging for 7 days of the liquid released from Si/Ca(Sr)-NCF mats. (a-d) TEM images of the crystals and the residual co-precipitation particles. (c and d) The shedding silica skin during the crystallization procedure (red arrows). (e and $f$ ) Lattice spacing analyses of the crystals of the aged releasing liquid. (g) XRD patterns of the Si/Ca(Sr)-NCF mats' leaching liquid. (h and i) SEM images of the crystals. The red membranes indicated the sheded silica wrapping the crystals and NPs.

Abbreviations: NCF, nano cellulose fiber; $\mathrm{Si} / \mathrm{Ca}(\mathrm{Sr})-\mathrm{NCF}$, the nano cellulose fiber mineralized with silica and carbonates; TEM, transmission electron microscopy; SAED, selected area electron diffraction; EDS, energy-dispersive X-ray spectrometry; XRD, X-Ray Diffraction; SEM, scanning electron microscopy; NPs, nano particles.

\section{In vitro Anti-Bacterial Ability}

The results of bacteria colonies counting illustrated that all the testing groups have significant antibacterial effects than compare groups at 3 time points in the representative photos and anti-bacterial ratios (Figure 6). The antibacterial ratios of the four mineralized groups were $17.33 \%, 30.18 \%, 36.13 \%, 46.17 \%$ for 6 hours; $35.35 \%$, $45.27 \%, 54.31 \%, 68.97 \%$ for 12 hours, $69.43 \%, 68.66 \%$, $71.97 \%, 70.47 \%$ for 24 hours, respectively (Figure 6B).

\section{In vitro Cellular Studies with $\mathrm{Si} /$ $\mathrm{Ca}(\mathrm{Sr})-\mathrm{NCF}$ Mats \\ Cell Proliferation}

In the results of CCK-8 results, the OD value of $\mathrm{Si} / \mathrm{Ca}$ ( $\mathrm{Sr} 0)-\mathrm{NCF}$ and $\mathrm{Si} / \mathrm{Ca}(\mathrm{Sr}$ 0.01)-NCF were significantly higher than the control group at day 1,7 and 14 (Figure 7B). Significant decrease was present in $\mathrm{Si} / \mathrm{Ca}(\mathrm{Sr}$ $0.1)$-NCF group compared to control groups and no significant difference was found between $\mathrm{Si} / \mathrm{Ca}(\mathrm{Sr} 0)-\mathrm{NCF}$ and $\mathrm{Si} / \mathrm{Ca}(\mathrm{Sr}$ 0.01)-NCF groups at all time points (Figure 7B).

\section{Cell Adhesion and Morphology with $\mathrm{Si} / \mathrm{Ca}(\mathrm{Sr})-\mathrm{NCF}$ Mats}

Verified by the Live/Dead (Figure 7A) and the cellular skeleton staining (Figure $7 \mathrm{H}$ ), the proliferation and adhesion of the hDPCs on the $\mathrm{Si} / \mathrm{Ca}(\mathrm{Sr})-\mathrm{NCF}$ mats had been demonstrated. Dead cells were obvious in $\mathrm{Si} / \mathrm{Ca}(\mathrm{Sr} 0.1)$ NCF group (Figure 7Ae1-e3) which was in accordance with the CCK-8 results (Figure 7B). For cell adhesion, the cell nucleus stained by PI grew into the fibrous structure (Figure $7 \mathrm{H}$ ) showing decreased nucleus density in the $\mathrm{Si} /$ $\mathrm{Ca}(\mathrm{Sr}$ 0.1)-NCF (Figure 7He1-e4) in accordance with CCK-8 and Live/Dead staining. Dense microfilaments and nucleus were presented in $\mathrm{Si} / \mathrm{Ca}(\mathrm{Sr} 0.01)-\mathrm{NCF}$ and $\mathrm{Si} / \mathrm{Ca}(\mathrm{Sr} 0.05)-\mathrm{NCF}$ groups indicating the preferable proliferation and adhesion activity.

\section{Alkaline Phosphatase (ALP) Activity and RT-qPCR for Osteogenesis-Related Gene Expression}

The ALP activity representing the matrix remineralization ability had been explored on day 7 and day 14. Adding of low $\mathrm{Sr}^{2+}$ dose realized the statistically highest ALP activity compared with $\mathrm{Sr}^{2+}$ free and NCF groups on day 7 and 
NCF

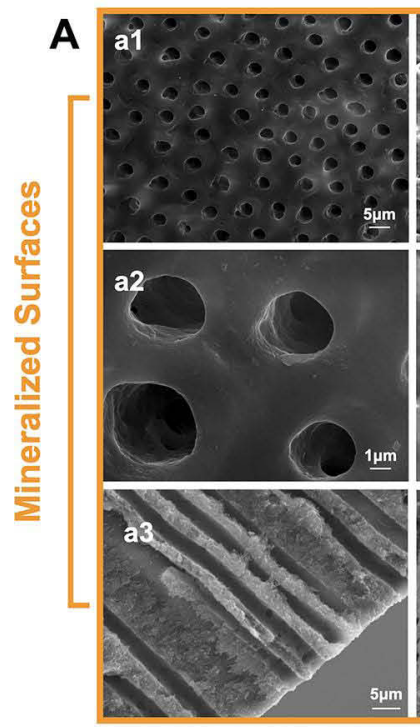

Si/Ca (Sro)-NCF

$\mathrm{Si} / \mathrm{Ca}(\mathrm{Sr} 0.01)-\mathrm{NCF}$

Si/Ca (Sr0.05)-NCF

Si/Ca (Sro.1)-NCF
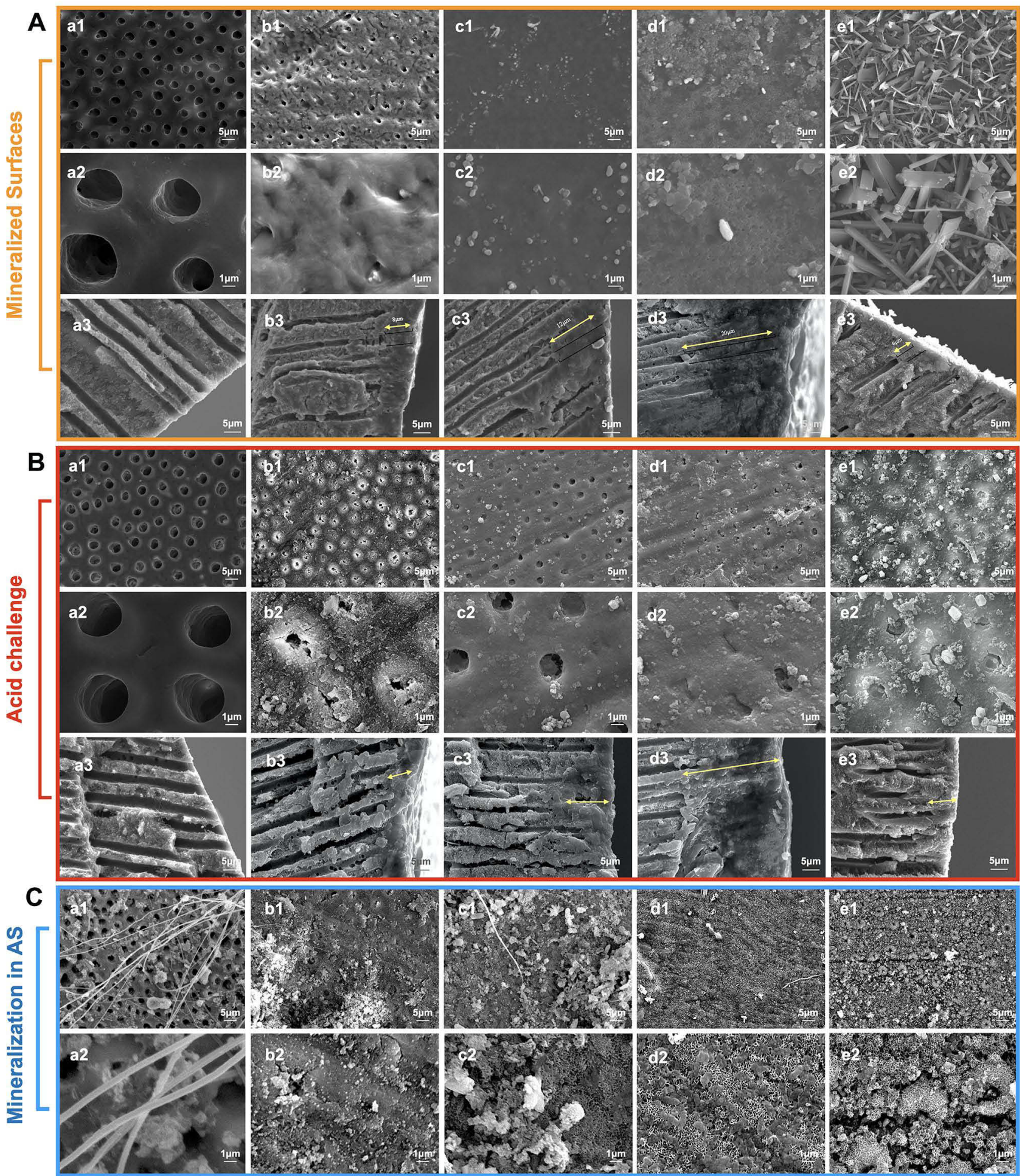

Figure 4 The SEM images of the remineralized dentine surfaces and longitudinal sections after applying the $\mathrm{Si} / \mathrm{Ca}(\mathrm{Sr})-\mathrm{NCF}$ mats. (A) SEM images presenting surface occluding and longitudinal infiltration of dentine discs (al-a3) in distilled water, (bl-b3) in $\mathrm{Si} / \mathrm{Ca}(\mathrm{Sr} \mathrm{0})-\mathrm{NCF}$ group, (cl-c3) in Si/Ca(Sr 0.0I)-NCF group, (dI-d3) in Si/Ca(Sr 0.05)-NCF group and (el-e3) in Si/Ca(Sr 0.I)-NCF group. (B) The SEM images presenting surface occluding and longitudinal infiltration after 6 wt\% citric acid leaching. Images of dentine discs (a I-a3) in distilled water, (bI-b3) in Si/Ca(Sr 0)-NCF group, (cl-c3) in Si/Ca(Sr 0.0I)-NCF group, (dI-d3) in Si/Ca(Sr 0.05)-NCF group, and (el-e3) in $\mathrm{Si} / \mathrm{Ca}$ (Sr 0.I)-NCF group. (C) The SEM images after immersing in artificial saliva for 7 days. Images presenting surface occluding (a I-a2) in distilled water, (bI-b2) in Si/Ca ( $\mathrm{Sr} 0)-\mathrm{NCF}$ group, (cl-c2) in $\mathrm{Si} / \mathrm{Ca}(\mathrm{Sr} 0.0 \mathrm{I})-\mathrm{NCF}$ group, (dI-d2) in $\mathrm{Si} / \mathrm{Ca}(\mathrm{Sr} 0.05)-\mathrm{NCF}$ group, and (el and e2) in $\mathrm{Si} / \mathrm{Ca}(\mathrm{Sr} 0 . \mathrm{I})-\mathrm{NCF}$ group.

Abbreviations: SEM, scanning electron microscopy; NCF, nano cellulose fiber; $\mathrm{Si} / \mathrm{Ca}(\mathrm{Sr})-\mathrm{NCF}$, the nano cellulose fiber mineralized with silica and carbonates. 

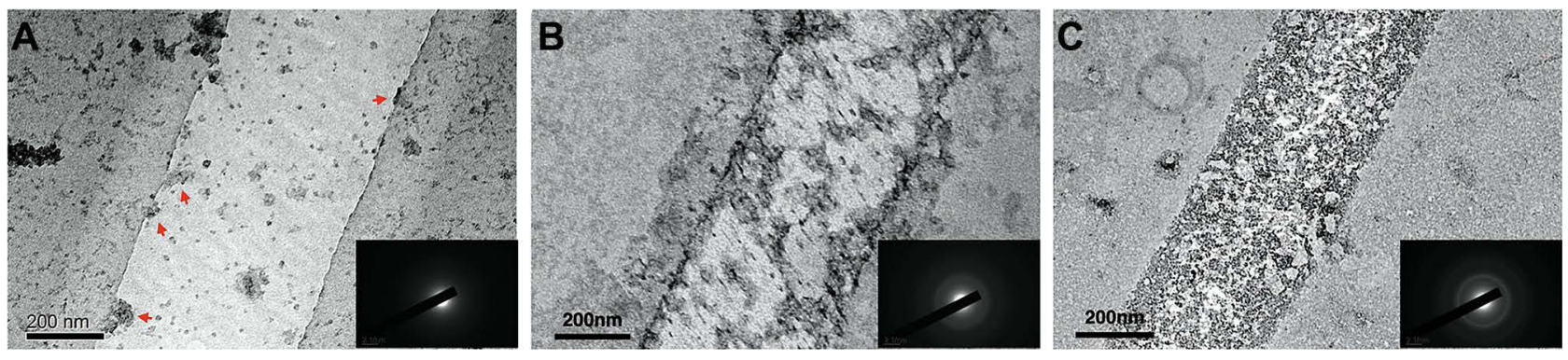

Figure 5 The TEM images of the Si/Ca(Sr0.05)-NCF releasing liquid mineralized type I collagen for I h, $12 \mathrm{~h}$ and $24 \mathrm{~h}$ with uranium acetate dyeing. The image revealed dispersed nanospheres (red arrows) attaching to the collagen and the SAED results indicated (A) the amorphous SAED phase at time point I h, (B) SAED results indicated polycrystals at $12 \mathrm{~h},(\mathbf{C})$ SAED results indicated polycrystals at $24 \mathrm{~h}$.

Abbreviations: $\mathrm{Si} / \mathrm{Ca}(\mathrm{Sr})-\mathrm{NCF}$, the nano cellulose fiber mineralized with silica and carbonates; TEM, transmission electron microscopy; SAED, selected area electron diffraction.

14 (Figure 7C). While the OD value in middle and high $\mathrm{Sr}^{2+}$ groups showed no significant difference with compare group (Figure 7C).

Osteogenesis and odontoblastic-related genes in hDPCs, including ALP (early marker for osteogenic differentiation and odontoblast differentiation), OCN (late marker for osteogenic differentiation and odontoblastic differentiation), Runx2 (vital transcription maker for bone formation), and OPN (crucial marker in apatite crystals) were significantly upregulated in $\mathrm{Si} / \mathrm{Ca}(\mathrm{Sr} 0.01)-\mathrm{NCF}$ group at day 7 (Figure 7D-G). ${ }^{25,26}$

\section{Discussion}

In present research, $\mathrm{Si} / \mathrm{Ca}(\mathrm{Sr})-\mathrm{NCF}$ mats were successfully fabricated and $\mathrm{Si} / \mathrm{Ca}(\mathrm{Sr})$ NPs releasing from the mats conducted desirable anti-acid biomimetic dentine remineralization, antibacterial activity with E. faecalis and biocompatibility with hDPCs (Scheme 1). Moreover, the applying of $\mathrm{Sr}^{2+}$ yielded several benefits: (1) middle $\mathrm{Sr}^{2+}$ adding in the system conducted continuous mechanical tubular occluding, preferable acid resistance and remineralization in AS; (2) ALP activity was improved by limited $\mathrm{Sr}^{2+}$ adding.

Remarkably, continuous $\mathrm{Si} / \mathrm{Ca}(\mathrm{Sr})$ NPs release from $\mathrm{Si} /$ $\mathrm{Ca}(\mathrm{Sr})$ - NCF mats was verified by the nanoparticles in leaching liquid (Figure 3B), characteristic shell shedding images in TEM results (Figure $3 \mathrm{Bc}, \mathrm{Bd}$ ) and the ion release assay (Figure $3 \mathrm{~A}$ ). In present study, the mineralized NCF mats provided silica rich and alkalescence environment which is essential for the $\mathrm{Si} / \mathrm{Ca}(\mathrm{Sr})$ NPs selfassembling. ${ }^{14}$ The stabilizing effect of this inorganic silica stabilized amorphous precursor was confirmed in the TEM images (Figure 3B). Even in the images after aging for a week, there were still isolated nanoparticles in the releasing dilution showing the long term carbonates stabilization (Figure 3C). As a carrier and storage, the mineralized NCF mats with disordered nano fibers and partial crystallization (Figure 1) also showed low elastic modulus (Figure 2D) and high surface hydrophilicity (Figure 2C) in low $\mathrm{Sr}^{2+}$ group making it easy to apply as lining and medical dressing. Base films combining with silica and carbonate components was reported before. ${ }^{27}$ The explanation might be the negative charged NCF surface interacted with the positive charged cations synergistically with the silica and from a whole NCF (-OH) $-\mathrm{Ca}^{2+} / \mathrm{Sr}^{2+}$-silanol (Si-OH) network.

Apart from the stabilization effect of the silica shell, the $\mathrm{Sr}^{2+}$ addition further promoted particle dispersion on dentine surfaces. Interestingly, uniform segmental particles connected onto fibrous mat (Figure 1d1), homogeneous dentine surface covering (Figure 4Ad1 and d2), deep longitudinal sedimentation (Figure 4Ad3), preferable results of anti-acid (Figure 4Bd1-d3) and remineralization in AS (Figure 4Cd1 and d2) were all showed in the low and middle $\mathrm{Sr}^{2+}$ containing groups. As the tendency of polycrystal ball forming in $\mathrm{Sr}^{2+}$ free group, the micrometer sized polycrystal particles were too large to obstruct the 1-2 $\mu \mathrm{m}$ diameter tubular openings (Figure 1b1). This polycrystal sphere was previously reported and explained as the much stronger interaction between $\mathrm{Ca}^{2+}$ and silicate ions than the homologous such as $\mathrm{Sr}^{2+}$ and $\mathrm{Be}^{2+} \cdot{ }^{28,29}$ While, in the high $\mathrm{Sr}^{2+}$ concentration group, large blade shaped crystals also showed shorter infiltration (Figure 4Ae1-e3). Based on previous research indicating the increased anisotropic after $\mathrm{Sr}^{2+}$ addition, the possible explanation for the homogeneous particle dispersion may be that the appropriate amount of $\mathrm{Sr}^{2+}$ may competitively inhibit the coagulation of $\mathrm{CaCO}_{3}$, inducing a less violent 
A

NCF

$\mathrm{Si} / \mathrm{Ca}(\mathrm{Sr})$-NCF

$\mathrm{Si} / \mathrm{Ca}(\mathrm{Sr} 0.01)-\mathrm{NCF} \mathrm{Si} / \mathrm{Ca}(\mathrm{Sr} 0.05)-\mathrm{NCF}$

$\mathrm{Si} / \mathrm{Ca}(\mathrm{SrO}$.1)-NCF

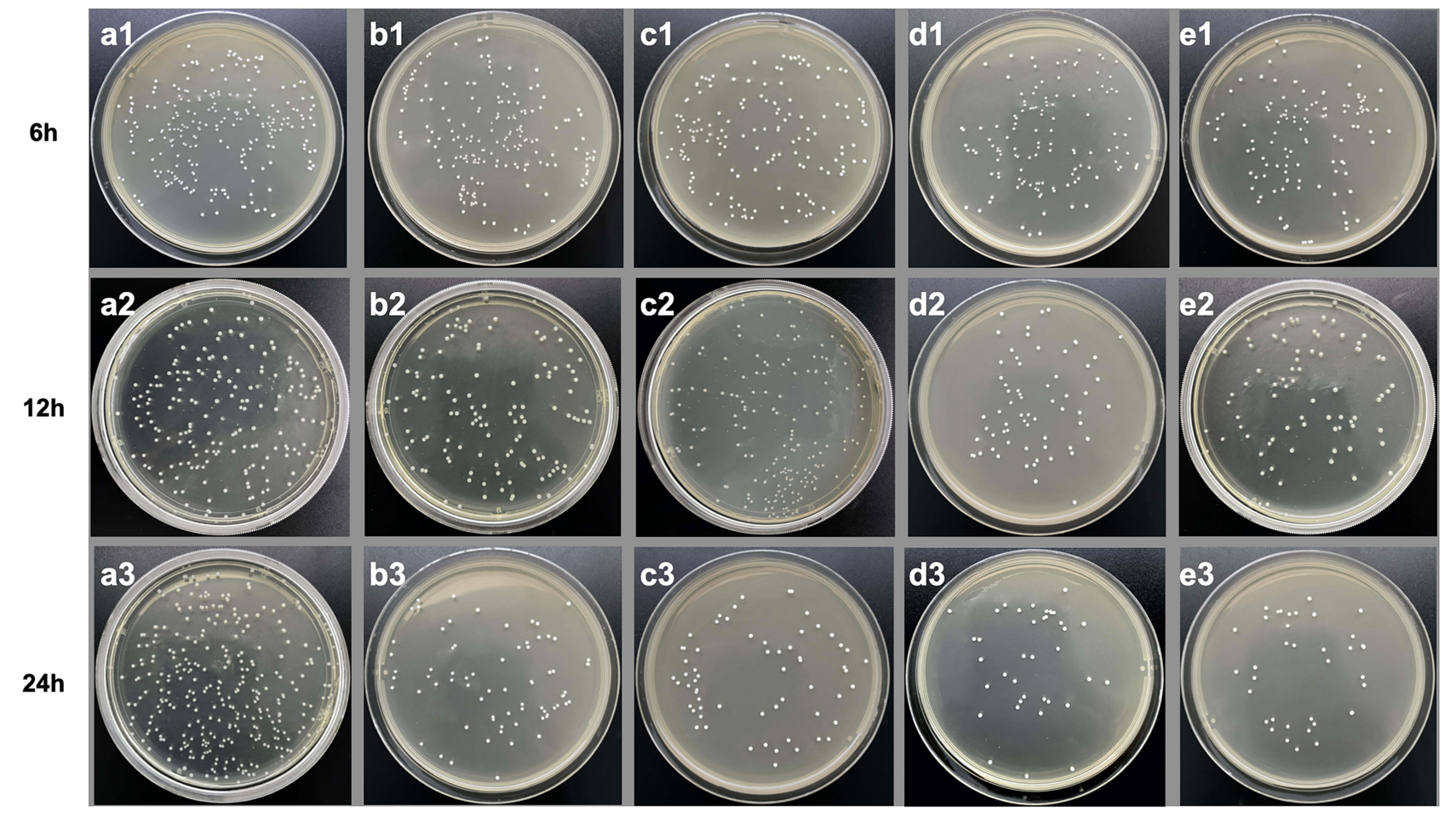

B

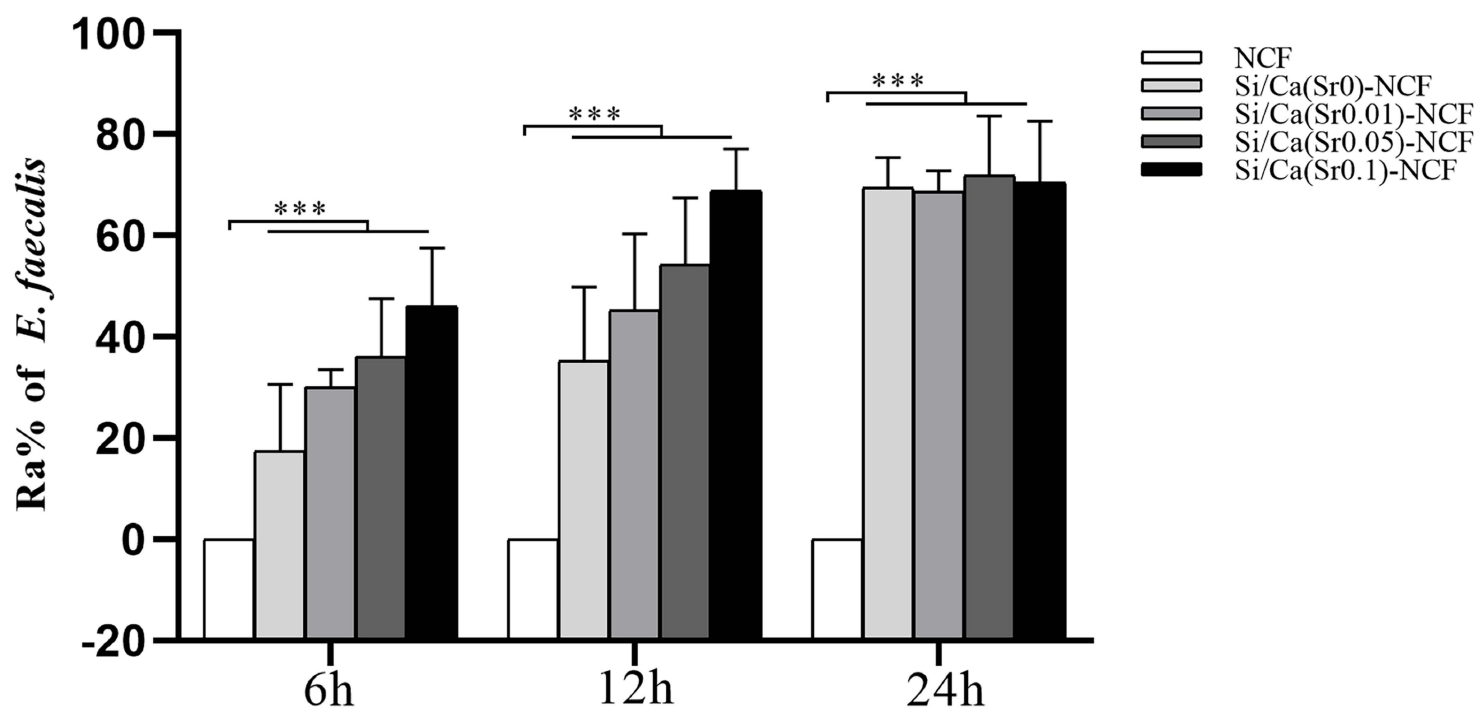

Time

Figure 6 The anti-bacteria tests for Enterococcus faecalis. (A) (al-el) The representative photographs of recultivated colonies of on agar plates at time points of 4 h, (a2-e2) $12 \mathrm{~h}$ and (a3-e3) $24 \mathrm{~h}$, and (B) the corresponding anti-bacteria ratios. $* * * *_{p}<0.00 \mathrm{I}$.

Abbreviations: NCF, nano cellulose fiber; $\mathrm{Si} / \mathrm{Ca}(\mathrm{Sr})-\mathrm{NCF}$, the NCF mineralized with silica and carbonates.

mineralization process and more uniform particle distribution.

In addition to the mechanical obstruction by $\mathrm{Si} / \mathrm{Ca}(\mathrm{Sr})$ NPs in site precipitation, the precursor NPs further conducted type I collagen biomimetic remineralization with the leaching liquid of middle $\mathrm{Sr}^{2+}$ group. Generally, small stabilizers $(<65 \mathrm{k}$ Da) were demanded for type I collagen intrafibrillar mineralization..$^{30,31}$ Oligomeric 


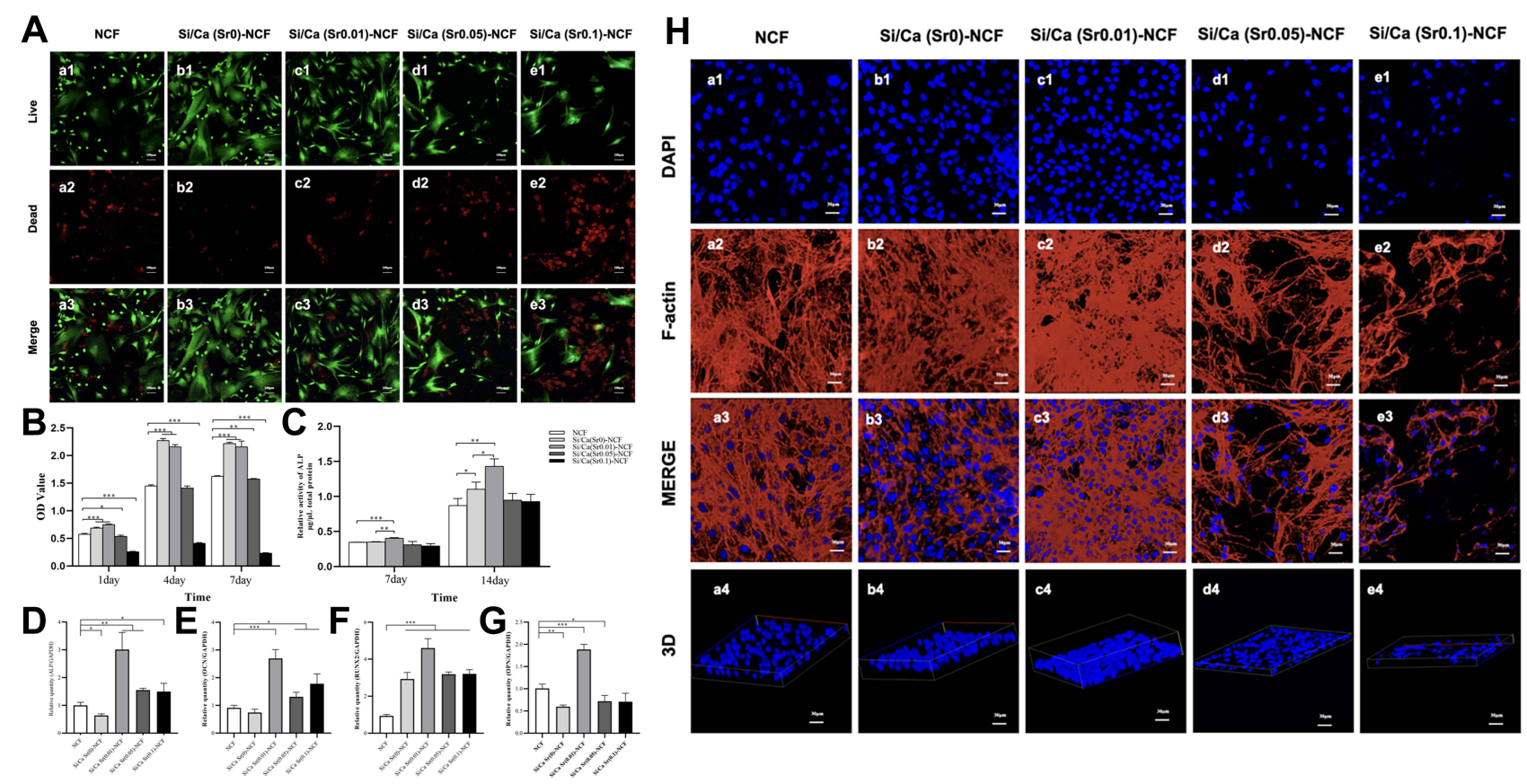

Figure 7 The hDPCs response to the Si/Ca(Sr)-NCF mats. (A) The Live/Dead fluorescent dyeing of hDPCs after cultured with Si/Ca(Sr)-NCF mats for I day. (B) The CCK8 results revealed the cell proliferation at time points of day I, 7 and 14. (C) The ALP activity of the hDPCs at day 7 and I4. (D-G) Gene expression levels of osteogenesisrelated markers: (D) ALP, (E) OCN, (F) Runx2, (E) OPN. (H) The cell adhesion with the $\mathrm{Si} / \mathrm{Ca}(\mathrm{Sr})-\mathrm{NCF}$ mats represented by the florescence images of the cell skeletons. $*_{p}<0.05, * *_{p}<0.01$, ***p $<0.001$.

Abbreviations: hDPCs, human dental pulp cells; NCF, nano cellulose fiber; Si/Ca(Sr)-NCF, the nano cellulose fiber mineralized with silica and carbonates; ALP, alkaline phosphatase. OCN, osteocalcin; Runx2, runt-related transcription factor; OPN, osteopontin.

silica was small enough and early collagen mineralization with polycrystal SAED rings confirmed that $\mathrm{Si} / \mathrm{Ca}(\mathrm{Sr}) \mathrm{NPs}$ as an inorganic silica stabilized precursor can induce dentine biomimetic remineralization (Figure 5). Moreover, the remineralized dentine tubular structure showing no regular parallel arrangement, but a continuous fused peritubular and tubular pattern, also indicated the prominent biomimetic dentine remineralization (Figure 4A and B).

According to the previous studies of silica-carbonate co-precipitation structure, the silica shells remain after the acid challenge. ${ }^{14,32}$ In the SEM images after acid leaching, although the precipitation of different groups showed corrosions in varying degrees, the anti-acid effects were still reliable as the residual particle fusion was evident in $\mathrm{Sr}^{2+}$ containing groups (Figure 4B) and longitudinal depth illustrated no significant reduction (Figure 4Aa3-e3, Ba3-e3).

Based on the dentine occluding evaluation above, the all-in-one $\mathrm{Si} / \mathrm{Ca}(\mathrm{Sr})-\mathrm{NCF}$ mats realized 6-20 $\mu \mathrm{m}$ infiltration within 24 hours and conducted anti-acid biomimetic remineralization not only by mechanical in site precipitation, but also via dentine collagen infiltration. Preferable occluding effects were presented in low and middle $\mathrm{Sr}^{2+}$ groups. The tubular obstructing by hydrophilic mat covering in present study was convenient and timeefficient, as many strategies nowadays still requiring several steps for days with undefined obstructing depth and acid resistance.

With respect to biological properties, antibacterial and biocompatibility activity were evaluated (Scheme 1). E. faecalis is a dominant bacterium inside the root canal. Evading in tubular system and the remaining viable are recognized to be the reasons causing periapical diseases. ${ }^{33,34}$ In consideration of the infiltration potential, the antibacterial activity of the $\mathrm{Si} / \mathrm{Ca}(\mathrm{Sr})-\mathrm{NCF}$ mats was evaluated by co-cultured with the E. faecalis. In BG antibacterial study based on large dataset, researchers believe the antibacterial effect has correlations with the unfavorable interface shaped by immediate alkaline species release. ${ }^{35,36}$ Higher solubility and denser cation ion release would be the reasons why the high $\mathrm{Sr}^{2+}$ containing group showed better antibacterial effect on E. faecalis.

In view of the penetration activity, cytocompatibility of $\mathrm{Si} / \mathrm{Ca}(\mathrm{Sr})-\mathrm{NCF}$ remineralization mats was another issue to be explored. After co-culturing with the hDPCs, the adhesion, proliferation and ALP activities were evaluated (Figure 7). Based on the research, $\mathrm{Sr}^{2+}$ promotes osteogenesis in mature 


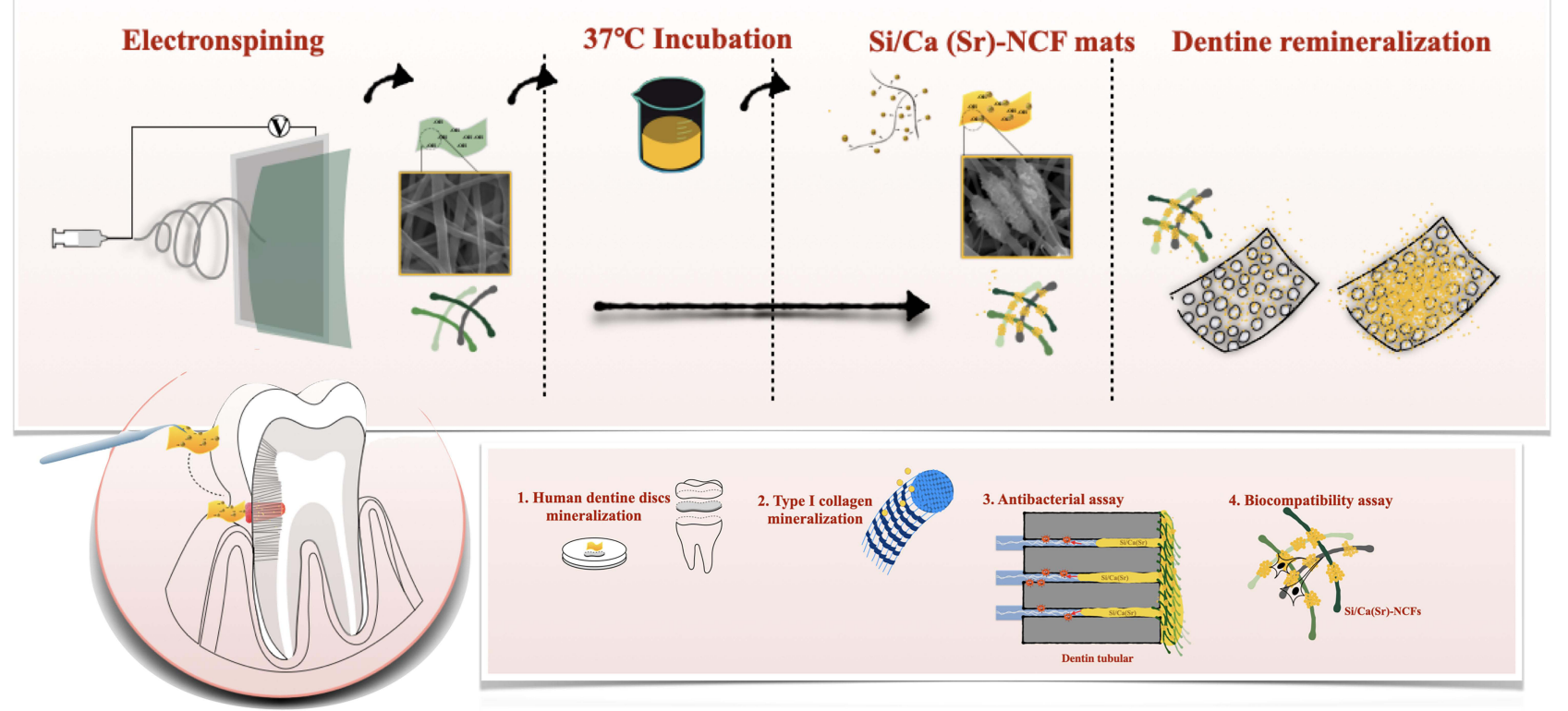

Scheme I Schematic illustration of $\mathrm{Si} / \mathrm{Ca}(\mathrm{Sr})-\mathrm{NCF}$ mats application to conduct multifunctional remineralization in dentine hypersensitivity model. Si/Ca(Sr)-NCF mats were assembled by electrospinning NCF mats and mineral loading. The dentine tubular obstruction effects were evaluated with (I) in vitro dentine discs, (2) the type I collagen model, (3) the antibacterial activity and (4) cytocompatibility with human dental pulp cells. $\mathrm{Si} / \mathrm{Ca}(\mathrm{Sr}) \mathrm{NPs}$ were continuously released from the minerals $\left(\mathrm{Ca}{ }^{2+} / \mathrm{Sr}^{2+}\right)$ and silica rich mat surfaces facilitating the dentine remineralization not only through mechanical occluding but also homogeneous nucleation of the type I collagen. The antibacterial activity and cytocompatibility further indicated the multifunctional all-in-one $\mathrm{Si} / \mathrm{Ca}(\mathrm{Sr})-\mathrm{NCF}$ mats is a promising candidate to treat the dentine hypersensitivity. Abbreviations: NCF, nano cellulose fiber; NPs, nano particles; Si/Ca(Sr)-NCF, the nano cellulose fiber mineralized with silica and carbonates.

osteocytes in a dose dependent manner within the concentration from $10-1000 \mathrm{uM}^{37,38}$ Similar $\mathrm{Sr}^{2+}$ dose dependent osteo-induction and cell viability is also reported with ALP activity promotion in concentration of $0.1-2.5 \mathrm{mM}$ in hDPCs. ${ }^{39}$ Based on the $\mathrm{Sr}$ ion release within 12 days, the high $\mathrm{Sr}^{2+}$ containing group $(4.75 \mathrm{mM}$, Figure $3 \mathrm{Ad}-\mathrm{f})$ showing cytotoxicity, and low $\mathrm{Sr}^{2+}$ containing group $(0.48 \mathrm{mM}$, Figure $3 \mathrm{Ad}-\mathrm{f}$ ) showing ALP promotion and cytocompatibility with hDPCs in present study could be explained.

As high calcified tissue, the development of hard tissue is closely related to the bone formation. The $\mathrm{Si} / \mathrm{Ca}(\mathrm{Sr} 0.01)$ NCF releasing liquid with low $\mathrm{Sr}^{2+}$ concentration significantly improved the gene expression for the early and late odontoblastic differentiation. While in the high $\mathrm{Sr}^{2+}$ group, the proliferation and odontoblastic differentiation were inhibited. These results were in accordance with the dose dependence results. ${ }^{37}$ In addition, the potential mechanism for $\mathrm{Sr}^{2+}$ may be that the $\mathrm{Sr}^{2+}$ promote osteoblast differentiation via the CaSR pathway, which is similar to the Ca ions. ${ }^{26}$ While in present study, the low $\mathrm{Sr}^{2+}$ group significantly improved the ALP activities and the related gene expression compared with the pure calcium group (Figure 7D-G). The underlying cell differentiation promoting mechanism of $\mathrm{Sr}^{2+}$ needs to be further explored.

Fundamentally, this in vitro study is still limited as the oral activities are accompanied by more complicated physico-chemical interactions. The ion release in distilled water in present study may also be quite different with the release in saliva liquid. ${ }^{40}$ Therefore, further studies such as acid challenge for longer time, wear resistance tests, and the in vivo experiments are indispensable.

\section{Conclusion}

Present study confirmed that the $\mathrm{Si} / \mathrm{Ca}(\mathrm{Sr})-\mathrm{NCF}$ system with low and middle $\mathrm{Sr}^{2+}$ containing $\left(0.48-2.59 \mathrm{mM} \mathrm{Sr}^{2+}\right.$ release) successfully realized acid-resistant, bacteriostatic, and low cytotoxic dentine biomimetic remineralization. This multifunction all-in-one $\mathrm{Si} / \mathrm{Ca}(\mathrm{Sr})-\mathrm{NCF}$ system was convenient and effective to utilize as the $\mathrm{Si} / \mathrm{Ca}(\mathrm{Sr}) \mathrm{NPs}$ continuously releasing from the carrier mats. Moreover, dentine tubular bacterial E. faecalis was inhibited, and $\mathrm{hDPCs}$ proliferation and ALP activity representing matrix mineralization was promoted. The multifunction $\mathrm{Si} / \mathrm{Ca}(\mathrm{Sr})-$ NCF system, with soft NCF basement, which may be easily 
applied onto complicated dentine surfaces such as the areas adjacent to pulp cavity and with potential bacterial infections, could be a promising candidate managing the $\mathrm{DH}$ in the future.

\section{Acknowledgments}

This work was financially supported by the National Nature Science Foundation of China (NO. 82001094).

\section{Disclosure}

The authors declare that they have no conflict of interests.

\section{References}

1. Favaro Zeola L, Soares PV, Cunha-Cruz J. Prevalence of dentin hypersensitivity: systematic review and meta-analysis. $J$ Dent. 2019;81:1-6. doi:10.1016/j.jdent.2018.12.015

2. West N, Seong J, Davies M. Dentine hypersensitivity. Monogr Oral Sci. 2014;25:108-122. doi:10.1159/000360749

3. Thomas MS. Dentin hypersensitivity. $J$ Evid Base Dent Pract. 2011;142:220-228. doi:10.1016/S1532-3382(12)70043-X

4. Brannstrom M. Dentin sensitivity and aspiration of odontoblasts. J Am Dent Assoc. 1963;66:366-370. doi:10.14219/jada.archive. 1963.0104

5. Walters PA. Dentinal hypersensitivity: a review. J Contemp Dent Pract. 2005;6:107-117. doi:10.5005/jcdp-6-2-107

6. Yu J, Yang H, Li K, et al. A novel application of nanohydroxyapatite/ mesoporous silica biocomposite on treating dentin hypersensitivity: an in vitro study. $J$ Dent. 2016;50:21-29. doi:10.1016/j. jdent.2016.04.005

7. Liang K, Xiao S, Liu H, et al. 8DSS peptide induced effective dentinal tubule occlusion in vitro. Dent Mater. 2018;34(4):629-640. doi:10.1016/j.dental.2018.01.006

8. Niu LN, Zhang W, Pashley DH, et al. Biomimetic remineralization of dentin. Dent Mater. 2014;30:77-96. doi:10.1016/j.dental.2013.07.013

9. Poulsen S, Errboe M, Lescay Y, et al. Potassium containing toothpastes for dentine hypersensitivity. Cochrane Database Syst Rev. 2006;(3):CD001476. doi:10.1002/14651858.CD001476.pub2

10. Zhou YZ, Cao Y, Liu W, et al. Polydopamine-induced tooth remineralization. Acs Appl Mater Interfaces. 2012;4:6901-6910. doi:10.1021/am302041b

11. Liu Z, Shao C, Jin B, et al. Crosslinking ionic oligomers as conformable precursors to calcium carbonate. Nature. 2019;574 (7778):394-398. doi:10.1038/s41586-019-1645-x

12. Gower LB. Biomimetic model systems for investigating the amorphous precursor pathway and its role in biomineralization. Cheminform. 2009;40(5):4551-4627. doi:10.1021/cr800443h

13. Xu Z, Long J, Zhang N, et al. Strong mineralization ability of strontium zinc silicate: formation of a continuous biomorphic mineralized layer with enhanced osteogenic activity. Colloids Surf B Biointerfaces. 2019;176:420-430. doi:10.1016/j.colsurfb.2019. 01.026

14. Hyde ST, Carnerup AM, Larsson AK, et al. Self-assembly of carbonate-silica colloids: between living and non-living form. Phys A. 2004;339:24-33. doi:10.1016/j.physa.2004.03.045

15. Eiblmeier J, Kellermeier M, Deng M, et al. Bottom-up self-assembly of amorphous core-shell-shell nanoparticles and biomimetic crystal forms in inorganic silica-carbonate systems. Chem Mater. 2013;25:1842-1851. doi:10.1021/cm4003959

16. Kellermeier M, Melero-García E, Glaab F, et al. Stabilization of amorphous calcium carbonate in inorganic silica-rich environments. J Am Chem Soc. 2010;132(50):17859-17866. doi:10.1021/ja106959p
17. Kellermeier M, Melero-García E, Kunz W, et al. Local autocatalytic co-precipitation phenomena in self-assembled silica-carbonate materials. Colloids Surf B Biointerfaces. 2012;380:1-7. doi:10.1016/j. jcis.2012.05.009

18. Knaus J, Sommer M, Duchstein P, et al. Polar structure formation in solid solution of strontium-substituted fluorapatite-gelatin composites: from structural and morphogenetic aspects to pyroelectric properties. Chem Mater. 2020;32:8619-8632. doi:10.1021/acs.chemmater.0c02993

19. Ma KN, Huang D, Cai J, et al. Surface functionalization with strontium-containing nanocomposite coatings via EPD. Colloids Surf B Biointerfaces. 2016;146:97-106. doi:10.1016/j.colsurfb.2016.05.036

20. Deng H, Zhou X, Wang X, et al. Layer-by-layer structured polysaccharides film-coated cellulose nanofibrous mats for cell culture. Carbohydr Polym. 2010;80(2):474-479. doi:10.1016/j.carbpol.2009.12.004

21. Nakouzi E, Fares HM, Schlenoff JB, et al. Polyelectrolyte complex films influence the formation of polycrystalline micro-structures. Soft Matter. 2018;14(16):3164-3170. doi:10.1039/C7SM02466E

22. Wang Z, Sa Y, Sauro S, et al. Effect of desensitising toothpastes on dentinal tubule occlusion: a dentine permeability measurement and SEM in vitro study. J Dent. 2010;38:400-410. doi:10.1016/j.jdent.2010.01.007

23. João-Souza SH, Machado C, Lopes M, et al. Effectiveness and acid/ tooth brushing resistance of in-office desensitizing treatments-A hydraulic conductance study. Arch Oral Biol. 2018;96:130-136. doi:10.1016/j.archoralbio.2018.09.004

24. Nudelman F, Pieterse K, George A. The role of collagen in bone apatite formation in the presence of hydroxyapatite nucleation inhibitors. Nat Mater. 2010;9:1004-1009. doi:10.1038/nmat2875

25. Gan X, He KH, Qian BS, et al. The effect of glycine on the growth of calcium carbonate in alkaline silica gel. $J$ Cryst Growth. 2017;458:60-65. doi:10.1016/j.jcrysgro.2016.11.027

26. Qin W, Liu P, Zhang R, et al. JNK MAPK is involved in BMP-2-induced odontoblastic differentiation of human dental pulp cells. Connect Tissue Res. 2014;55:217-224. doi:10.3109/ 03008207.2014.882331

27. Huang D, Ma K, Cai X, et al. Evaluation of antibacterial, angiogenic, and osteogenic activities of green synthesized gap-bridging copper-doped nanocomposite coatings. Int $J$ Nanomedicine. 2017;12:7483-7500. doi:10.2147/IJN.S141272

28. Eiblmeier J, Dankesreiter S, Pfitzner A, et al. Crystallization of mixed alkaline-earth carbonates in silica solutions at high Ph. Cryst Growth Des. 2014;14:6177-6188. doi:10.1021/cg5004116

29. Nakouzi E, Rendina R, Palui G, et al. Effect of inorganic additives on the growth of silica-carbonate biomorphs. J Cryst Growth. 2016;452:166-171. doi:10.1016/j.jcrysgro.2015.12.042

30. Niu LN, Jee SE, Jiao K, et al. Collagen intrafibrillar mineralization as a result of the balance between osmotic equilibrium and electroneutrality. Nat Mater. 2017;16:370-378. doi:10.1038/nmat4789

31. Liu Y, Luo D, Kou XI, et al. Hierarchical intrafibrillar nanocarbonated apatite assembly improves the nanomechanics and cytocompatibility of mineralized collagen. Adv Funct Mater. 2012;23:1404-1411. doi:10.1002/adfm.201201611

32. Bittarello E, Massaro FR, Aquilano D. The epitaxial role of silica groups in promoting the formation of silica/carbonate biomorphs: a first hypothesis. $J$ Cryst Growth. 2010;312(3):402-412. doi:10.1016/j.jcrysgro.2009.11.004

33. George S, Kishen A, Song P. The role of environmental changes on monospecies biofilm formation on root canal wall by enterococcus faecalis. $J$ Endodontics. 2005;31:867-872. doi:10.1097/01. don.0000164855.98346.fc

34. Fan W, Li YY, Sun Q, et al. Calcium-silicate mesoporous nanoparticles loaded with chlorhexidine for both anti- Enterococcus faecalis and mineralization properties. $J$ Nanobiotechnol. 2016;14(1). doi:10.1186/s12951-016-0224-7

35. Echezarreta-López MM, Landin M. Using machine learning for improving knowledge on antibacterial effect of bioactive glass. Int J Pharm. 2013;453:641-647. doi:10.1016/j.jpharm.2013.06.036 
36. Liu J, Rawlinson SC, Hill RG, et al. Strontium-substituted bioactive glasses in vitro osteogenic and antibacterial effects. Dent Mater. 2016;32:412-422. doi:10.1016/j.dental.2015.12.013

37. Aimaiti A, Maimaitiyiming A, Boyong X, et al. Low-dose strontium stimulates osteogenesis but high-dose doses cause apoptosis in human adipose-derived stem cells via regulation of the ERK1/2 signaling pathway. Stem Cell Res Ther. 2017;8:282. doi:10.1186/s13287-0170726-8

38. Mohan BG, Suresh BS, Varma HK, et al. In vitro evaluation of bioactive strontium-based ceramic with rabbit adipose-derived stem cells for bone tissue regeneration. J Mater Sci Mater Med. 2013;24:2831-2844. doi:10.1186/s13287-017-0726-8
39. Huang M, Hill RG, Rawlinson SC. Strontium (Sr) elicits odontogenic differentiation of human dental pulp stem cells (hDPSCs): a therapeutic role for $\mathrm{Sr}$ in dentine repair? Acta Biomater. 2016;38:201-211. doi:10.1016/j.actbio.2016.04. 037

40. Pokrowiecki R, Wojnarowicz J, Zareba T, et al. Nanoparticles and human saliva: a step towards drug delivery systems for dental and craniofacial biomaterials. Int J Nanomedicine. 2019;14:9235-9257. PMID: 31819427; PMCID: PMC6886554. doi:10.2147/IJN. S221608

\section{Publish your work in this journal}

The International Journal of Nanomedicine is an international, peerreviewed journal focusing on the application of nanotechnology in diagnostics, therapeutics, and drug delivery systems throughout the biomedical field. This journal is indexed on PubMed Central, MedLine, CAS, SciSearch ${ }^{\mathbb{R}}$, Current Contents ${ }^{\mathbb{R}} /$ Clinical Medicine, $^{-}$
Journal Citation Reports/Science Edition, EMBase, Scopus and the Elsevier Bibliographic databases. The manuscript management system is completely online and includes a very quick and fair peer-review system, which is all easy to use. Visit http://www.dovepress.com/ testimonials.php to read real quotes from published authors. 